\title{
Lower Serum Levels of Interleukin-6 in a Population Sample with Symptoms of Depression Than in a Population Sample without Symptoms of Depression
}

\author{
J. PODLIPNÝ ${ }^{1}$, Z. HESS ${ }^{2}$, J. VRZALOVÁ ${ }^{3}$, H. ROSOLOVÁ ${ }^{4}$, J. BERAN $^{1}$, B. PETRLOVÁ ${ }^{4}$ \\ ${ }^{1}$ Department of Psychiatry, Charles University in Prague, Faculty of Medicine in Plzeň and \\ University Hospital Plzeň, Czech Republic, ${ }^{2}$ Department of Immunology and Allergology, Charles \\ University in Prague, Faculty of Medicine in Plzeň and University Hospital Plzeň, Czech Republic, \\ ${ }^{3}$ Department of Nuclear Medicine, University Hospital Plzeň, Czech Republic, ${ }^{4}$ Centre of \\ Preventive Cardiology, Second Department of Internal Medicine, Charles University in Prague, \\ Faculty of Medicine in Plzeň (Pilsen), Czech Republic
}

Received October 1, 2008

Accepted January 5, 2009

On-line February 27, 2009

\section{Summary}

In this study we compared the levels of interleukin (IL)-6, IL-8, IL10 and tumor necrosis factor-a (TNF-a) in population samples characterized by a high or low level of self-reported depression. We measured serum IL-6, IL-8, IL-10 and TNF-a in two cohorts which differed in scoring on the Zung Self-Rating Depression Scale (ZSDS). The group with a high score in ZSDS (average SDS index $=62.9$ ) was called DEP $(n=27)$, the group with a low score in ZSDS (average SDS index $=29.9$ ) was called NDEP $(n=16)$. The groups did not significantly differ in age, waist circumference and body mass index. For the assessment of serum cytokine levels multiplex immunoanalytic XMAP(LUMINEX) technology was used. We found lower IL-6 in the DEP group (medians; DEP $4.08 \mathrm{pg} / \mathrm{ml}$ vs. NDEP $6.11 \mathrm{pg} / \mathrm{ml}$ ) on the border of statistical significance in multiple regression analysis $(p=0.049)$. Serum levels of all other studied cytokines were not significantly different (medians; IL-8: DEP $2.18 \mathrm{pg} / \mathrm{ml}$ vs. NDEP $2.61 \mathrm{pg} / \mathrm{ml}$; IL-10: DEP $2.85 \mathrm{pg} / \mathrm{ml}$ vs. NDEP $2.94 \mathrm{pg} / \mathrm{ml}$; TNF-a: DEP $2.32 \mathrm{pg} / \mathrm{ml}$ vs. NDEP $2.30 \mathrm{pg} / \mathrm{ml}$ ). These results are in contradiction to the prevailing opinion that proinflammatory cytokine levels are elevated in people with symptoms of depression.

\section{Key words}

Depression • Psychoneuroimmunology • Cytokines • Inflammation

\section{Corresponding author}

Jiří Podlipný, Department of Psychiatry, Charles University in Prague, Faculty of Medicine in Plzeň, Alej Svobody 80, 30460 Plzeň (Pilsen), Czech Republic. Fax: +420 $377103956 . \quad$ E-mail: podlipny@fnplzen.cz

\section{Introduction}

Several pathophysiological mechanisms of depression have been postulated in the last decade. The inflammatory hypothesis of depression is one of them. A typical finding, which has been replicated several times and supports the inflammatory hypothesis of depression, is the elevation of blood pro-inflammatory cytokines such as interleukin (IL)-1, IL-6 and tumor necrosis factor- $\alpha$ (TNF- $\alpha$ ) in patients suffering from depression (Sluzewska et al. 1995, 1996, Maes et al. 1995, Berk et al. 1997, Sutcigil et al. 2007). For example, Penninx et al. (2003) published a study examining the difference in the plasma levels of IL-6, TNF- $\alpha$ and C-reactive protein (CRP) in a large cohort of well-functioning older people split into two groups according to the presence of the symptoms of depression measured on the self-report scale. The depressive group had significantly higher levels of all the three inflammatory markers (IL-6, TNF- $\alpha$ and CRP) in this study. 
On the other hand, a few studies found contradictory results (Katila et al. 1994, Brambilla and Maggioni 1998). For example, Kagaya et al. (2001) compared plasma levels of IL-1 $\beta$, IL-6, TNF- $\alpha$ and soluble interleukin-2 receptor (sIL-2R) in depressed patients and healthy controls (matched according to sex and age). There were no significant differences found between the groups in this study. Marques-Deak et al. (2007) obtained the same results. Furthermore, there were no differences in cytokine levels in depressed patients divided into subgroups according to the type of depression. In addition, both studies confirmed the elevation of cytokines after a pharmacological treatment of depression. These data altogether underline the fact that the results of the current research into the link between a depressive disorder and inflammatory markers are inconsistent.

The connection between the peripheral immune system and the brain is explained by the activation of the afferent neurons of the vagus nerve (fast pathway). It can also be explained by direct targeting of the amygdala and other brain regions after the diffusion of cytokines (IL-1 $\beta$ ) at the circumventricular organs and the choroid plexus (slow pathway) (Dantzer 2001). The "depressive reaction" of the brain after these stimuli is also called sickness behavior (Dantzer 2001, Müller and Schwarz 2007). The typical feature of sickness behavior is not only fever, but also weakness, inability to concentrate, reduced food intake, decreased interest in the surroundings, lethargy, listlessness and others. These features are similar to those symptoms observed in people suffering from depression.

We put the question whether we can confirm the hypothesis of altered levels of pro-inflammatory cytokines in the general population self-reporting symptoms of depression. The aim of this study was to compare serum concentrations of pro-inflammatory cytokines (IL-6, IL-8, TNF- $\alpha$ ) and of the antiinflammatory cytokine IL-10 in two groups of healthy volunteers with a different level of self-reported depression.

\section{Methods}

\section{Characteristics of participants}

The assessment of the serum cytokine levels (IL-6, IL-8, IL-10 and TNF- $\alpha$ ) was performed in participants who were enrolled in a cross-sectional study focused on the investigation of the trends and determinants of cardiovascular diseases called MONICA (The World Health Organization MONICA Project (monitoring trends and determinants in cardiovascular disease) 1988). In the period from January 2003 to January 2004 letters of invitation were sent to a total of 1050 healthy volunteers. They were invited to the Centre of Preventive Cardiology (CPC) at the Second Department of Internal Medicine, University Hospital in Plzeň (Pilsen), for the assessment of metabolic syndrome parameters. The study was approved by the local ethical committee. 340 of all the invited volunteers visited the $\mathrm{CPC}$, and written informed consents in accordance with the Declaration of Helsinki (2000) of the World Medical Association were obtained from them. The participants were physically examined, their anthropometric parameters were measured, they filled in a Czech version of the Zung Self-Rating Depression Scale (ZSDS) and blood samples were collected from them between 8:00 h and 10:00 $\mathrm{h}$ in the morning. A total of 32 participants had incomplete data from the ZSDS and therefore were excluded, which means that 308 participants remained. We selected 34 participants with the highest score in the ZSDS and 34 participants with the lowest score in the ZSDS for further investigation of cytokine levels.

\section{Assessment of the symptoms of depression}

The population sample was measured with a Czech version of the Zung Self-Rating Depression Scale (ZSDS) (Zung 1965) immediately before the blood sample withdrawal. The ZSDS is a well-known instrument used worldwide for the assessment of depression. Its sensitivity and validity was found to be adequate (Biggs et al. 1978). It is often used in general medical practice as a screening test. Its effectiveness as a screener has also been documented (Zung 1990). In this self-rating scale, the subject is asked to rate 20 items of which 10 are worded symptomatically positive and 10 symptomatically negative. Each item is scored according to its severity level on an ordinal scale (1-4), where 1 = "a little of the time", 2 = "some of the time", $3=$ "good part of the time" and $4=$ "most of the time". The result of the self-rating scale is a total of all items and ranges from 20 to 80 (the "raw score"). This raw score can be converted to the "SDS index" (SDSI) by dividing the raw score by the maximum possible score of 80 and multiplying it by 100 . For example, a person who scores 45 according to the raw score has got the value of SDSI equal to 56.25. The higher the SDSI is, the more the person is depressed. There were four following 
Table 1. Characteristics of the DEP and NDEP groups.

\begin{tabular}{lccc}
\hline & $\begin{array}{c}\text { DEP }(\mathbf{n}=\mathbf{2 7}) \\
\text { mean ( } \pm \text { SD) }\end{array}$ & $\begin{array}{c}\text { NDEP (n=16) } \\
\text { mean ( } \pm \text { SD) }\end{array}$ & P \\
\hline SDSI & $62.9( \pm 4.8)$ & $29.9( \pm 2.7)$ & $<0.000001^{*}$ \\
BMI $\left(\mathrm{kg} / \mathrm{m}^{2}\right)$ & $27.3( \pm 5.7)$ & $25.3( \pm 2.8)$ & $\mathrm{NS}^{*}$ \\
Waist circumference $(\mathrm{cm})$ & $90.7( \pm 16.3)$ & $86.2( \pm 7.8)$ & $\mathrm{NS}^{*}$ \\
Age (years) & $53.3( \pm 9.1)$ & $49.3( \pm 10.5)$ & $\mathrm{NS}^{*}$ \\
\hline
\end{tabular}

DEP = group with the highest SDSI; NDEP = group with the lowest SDSI; SDSI = SDS index of the Zung Self-Rating Depression Scale; $\mathrm{BMI}=$ body mass index; SD = standard deviation; NS = statistically non-significant; * t-test.

thresholds of the SDSI proposed to measure the severity of depression according to ZSDS: $25-49=$ no or insignificant symptomatology; 50-59 = mild depression; 60-69 = moderate depression; 70-100 = severe depression (Barrett et al. 1978).

\section{Measurement of serum cytokine levels}

Multiplex immunoanalytic xMAP(LUMINEX) technology was used for the measurement of IL-6, IL-8, IL-10 and TNF- $\alpha$ serum levels. This technology combines sandwich immunoassay and flow cytometry and has enabled us to analyze all the studied proteins in one analysis and one sample aliquot. The xMAP technology is based on binding the studied proteins to the antibodies linked to microspheres with an internal spectral code referring to protein identity. The amounts of the bound proteins are determined by a second antibody connected with a fluorescent molecule. The measurement is performed on a special flow cytometer, which determines the spectral code of microspheres - the identity of proteins - after an excitation by the first laser. After an excitation by the second laser it detects the amount of the second antibody on the microspheres - the quantity of protein in the sample. The concentrations of proteins are assessed according to standard calibration curves assayed with unknown samples (Kellar and Iannone 2002).

The venous blood samples were drawn after an overnight fast. The aliquots of serum samples were stored at $-70{ }^{\circ} \mathrm{C}$. The aliquots were thawed at a laboratory temperature before the analysis. Commercially available kits - Human Cardiovascular Disease LINCOplex Panel 3 and Human Adipokine Panel B (Linco Research, USA) were used. The measurement was performed with the Luminex 100 instrument and the Luminex 100 IS software (Luminex Corporation, USA). The analysis was performed according to the manufacturer's instructions.
For all analytes 50 beads were set as a minimum beads/event criterion for result accuracy. If it was not possible for some measurement to reach this criterion, the result was excluded. Only the participants with complete data (levels of all proteins) were enrolled into the statistics. 25 participants were therefore excluded from further statistical analysis, thus 43 of them remained.

\section{Data analysis}

We used t-test for statistical analysis in the normal distribution of data, which was the case of SDSI, body mass index, waist circumference and age. In the case of nonparametric distribution of data Wilcoxon rank sum test was used and this was the case of the levels of all studied cytokines. Multiple regression analysis for dependent variables of serum levels of cytokines and independent variables SDSI, age, sex and body mass index (BMI) was calculated. The level of significance was set at $\mathrm{p}<0.05$. The STATA software (College Station, TX: Stata Corporation, 2002) was used.

\section{Results}

Complete serum cytokine levels were obtained from 27 participants with the highest SDSI (the DEP group) and from 16 participants with the lowest SDSI (the NDEP group). The comparison of these two groups regarding the mean SDSI, BMI, waist circumference and age is presented in Table 1. The difference in SDSI is statistically significant, the differences in all the other characteristics are not statistically significant (Table 1). There were more female participants (19 women, 8 men) in the DEP group and more male participants $(11 \mathrm{men}$, 5 women) in the NDEP group. There were no significant differences in BMI, waist circumference and age between those participants whose serum cytokine levels were either not measured or incomplete cytokine levels were 
Table 2. Levels of IL-10, IL-8, IL-6 and TNF-a in a group of participants with a high level of self-reported symptoms of depression (the DEP group) and with a low level of self-reported symptoms of depression (the NDEP group).

\begin{tabular}{|c|c|c|c|c|c|c|}
\hline & \multicolumn{2}{|c|}{$\begin{array}{c}\text { DEP group } \\
(\mathrm{n}=\mathbf{2 7})\end{array}$} & \multicolumn{2}{|c|}{$\begin{array}{c}\text { NDEP group } \\
(\mathrm{n}=16)\end{array}$} & \multirow[t]{2}{*}{$\mathbf{P}^{*}$} & \multirow[t]{2}{*}{$\mathbf{P} * *$} \\
\hline & median & $Q_{0.25}-Q_{0.75}$ & median & $Q_{0.25}-Q_{0.75}$ & & \\
\hline IL-10 (pg/ml) & 2.85 & $1.79-3.71$ & 2.94 & $2.34-3.23$ & NS & NS \\
\hline$I L-8(p g / m l)$ & 2.18 & $1.85-2.61$ & 2.61 & $1.60-2.90$ & NS & NS \\
\hline$I L-6(p g / m l)$ & 4.08 & $2.12-8.17$ & 6.11 & $2.24-14.98$ & NS & 0.049 \\
\hline$T N F-\alpha(p g / m l)$ & 2.32 & $1.73-2.87$ & 2.30 & $1.42-3.02$ & NS & NS \\
\hline
\end{tabular}

$\mathrm{Q}_{0.25}=$ lower quartile; $\mathrm{Q}_{0.75}=$ upper quartile; $\mathrm{NS}=$ statistically nonsignificant; *Wilcoxon rank sum test; **multiple regression analysis, adjusted for sex, age and BMI.

obtained $(\mathrm{n}=265)$ and both the DEP and NDEP groups $(\mathrm{n}=43)$.

The medians of cytokine levels of the particular groups are presented in Table 2. We did not find significant differences in IL-10, IL-8 and TNF- $\alpha$ serum levels between the DEP and NDEP group. There was a significant difference in IL-6 level between the DEP and NDEP group when assessed by multiple regression analysis $(4.08 \mathrm{pg} / \mathrm{ml}$ in DEP vs. $6.11 \mathrm{pg} / \mathrm{ml}$ in NDEP; $\mathrm{p}=0.049$ ). Surprisingly, the IL-6 serum level in people with symptoms of depression was lower, however, the difference is on the border of statistical significance.

\section{Discussion}

The major finding of this study is that the participants with a very high level of self-reported symptoms of depression had a significantly lower serum level of IL-6 than the participants with a very low level of self-reported symptoms of depression. This is a surprising result and it is in contradiction to the prevalent opinion in psychoneuroimmunology. On the other hand, this result underlines the inconsistency of the observations because similar results have also been published (Haack et al. 1999). The statistical significance of a lower IL-6 level in the DEP group was revealed when multiple regression analysis was performed and the results were adjusted for possible confounders. The strongest confounder for IL- 6 was sex (beta $=0.25 ; \mathrm{p}=0.155$ ), which corresponds to the high proportion of female participants in the DEP group and the low proportion of female participants in the NDEP group. None of the confounder variables reached the predefined level of statistical significance.

In this study, we found no significant difference in the serum TNF- $\alpha$ level between the DEP and NDEP group. Most studies found increased TNF- $\alpha$ levels in major depression when compared to healthy subjects (Lanquillon et al. 2000, Mikova et al. 2001). We did not find any difference in IL-8 levels between the DEP and NDEP group. One study found an elevation of IL-8 in patients suffering from bipolar depression compared to healthy subjects ( $\mathrm{O}^{\prime}$ Brien et al. 2006). The levels of IL-10 in the DEP and NDEP group were not significantly different in our study either. IL10 ranks among anti-inflammatory cytokines and suppresses the production of other cytokines. It is presumed not to be altered in people with depression. One study found an increased secretion of IL-10 in culture supernatant after exposure to therapeutic plasma concentrations of antidepressants (clomipramine and sertraline) (Maes et al. 1999).

This study, however, has several limitations. First of all, we did not compare a sample of participants suffering from depressive disorder with healthy people, yet we compared participants self-reporting depressive symptoms with those who did not report it. Therefore our results can be biased by this fact, which means that people who feel depressed (and score so in the ZSDS), show a lower serum level of IL-6, but this is not the case in people who suffer from a depressive illness. Furthermore, the difference in IL-6 regarding SDSI is on the border of predefined level of statistical significance and therefore we must interpret it very cautiously. Another limitation is the small sample size. It is necessary to replicate the finding in larger cohorts. In conclusion, the results of the present study do not support most of the previous findings and should serve as a challenge to further research in psychoneuroimmunology. 


\section{Conflict of Interest}

There is no conflict of interest.

\section{Acknowledgements}

The study was supported by the research grant of the Internal Grant Agency of the Ministry of Health, Czech Republic, NR8279-3/2005 and by the research project VZ MSM 0021620812.

\section{References}

BARRETT J, HURST MW, DiSCALA C, ROSE RM: Prevalence of depression over a 12-month period in a nonpatient population. Arch Gen Psychiatry 35: 741-744, 1978.

BERK M, WADEE AA, KUSCHKE RH, O'NEILL-KERR A: Acute phase proteins in major depression. J Psychosom Res 43: 529-534, 1997.

BIGGS JT, WYLIE LT, ZIEGLER VE: Validity of the Zung self-rating depression scale. Br J Psychiat 132: 381-385, 1978.

BRAMBILLA F, MAGGIONI M: Blood levels of cytokines in elderly patients with major depressive disorder. Acta Psychiatr Scand 97: 309-313, 1998.

DANTZER R: Cytokine-induced sickness behavior: where do we stand? Brain Behav Immun 15: 7-24, 2001.

HAACK M, HINZE-SELCH D, FENZEL T, KRAUS T, KÜHN M, SCHULD A, POLLMÄCHER T: Plasma levels of cytokines and soluble cytokine receptors in psychiatric patients upon hospital admission: effects of confounding factors and diagnosis. $J$ Psychiatr Res 33: 407-418, 1999.

KAGAYA A, KUGAYA A, TAKEBAYASHI M, FUKUE-SAEKI M, SAEKI T, YAMAWAKI S, UCHITOMI Y: Plasma concentrations of interleukin-1beta, interleukin-6, soluble interleukin-2 receptor and tumor necrosis factor alpha of depressed patients in Japan. Neuropsychobiology 43: 59-62, 2001.

KELLAR KL, IANNONE MA: Multiplexed microsphere-based flow cytometric assays. Exp Hematol 30: 1227-1237, 2002.

KATILA H, APPELBERG B, HURME M, RIMON R: Plasma levels of interleukin-1 beta and interleukin-6 in schizophrenia, other psychoses, and affective disorders. Schizophr Res 12: 29-34, 1994.

LANQUILLON S, KRIEG JC, BENING-ABU-SHACH U, VEDDER H: Cytokine production and treatment response in major depressive disorder. Neuropsychopharmacology 22: 370-379, 2000.

MAES M, MELTZER HY, BOSMANS E, BERGMANS R, VANDOOLAEGHE E, RANJAN R, DESNYDER R: Increased plasma concentrations of interleukin-6, soluble interleukin-6, soluble interleukin-2 and transferrin receptor in major depression. J Affect Disord 34: 301-309, 1995.

MAES M, SONG C, LIN AH, BONACCORSO S, KENIS G, DE JONGH R, BOSMANS E, SCHARPÉ S: Negative immunoregulatory effects of antidepressants: inhibition of interferon-gamma and stimulation of interleukin-10 secretion. Neuropsychopharmacology 20: 370-379, 1999.

MARQUES-DEAK AH, NETO FL, DOMINGUEZ WV, SOLIS AC, KURCGANT D, SATO F, ROSS JM, PRADO EB: Cytokine profiles in women with different subtypes of major depressive disorder. J Psychiatr Res 41: 152$159,2007$.

MIKOVA O, YAKIMOVA R, BOSMANS E, KENIS G, MAES M: Increased serum tumor necrosis factor alpha concentrations in major depression and multiple sclerosis. Eur Neuropsychopharmacol 11: 203-208, 2001.

MÜLLER N, SCHWARZ MJ: The immune-mediated alteration of serotonin and glutamate: towards an integrated view of depression. Mol Psychiatry 12: 988-1000, 2007.

O'BRIEN SM, SCULLY P, SCOTT LV, DINAN TG: Cytokine profiles in bipolar affective disorder: focus on acutely ill patients. J Affect Disord 90: 263-267, 2006.

PENNINX BW, KRITCHEVSKY SB, YAFFE K, NEWMAN AB, SIMONSICK EM, RUBIN S, FERRUCCI L, HARRIS T, PAHOR M: Inflammatory markers and depressed mood in older persons: results from the Health, Aging and Body Composition study. Biol Psychiatry 54: 566-572, 2003. 
SLUZEWSKA A, RYBAKOWSKI J, LACIAK JK, MACKIEWICZ A, SOBIESKA M, WIKTOROWICZ K: Interleukin-6 serum levels in depressed patients before and after treatment with fluoxetine. Ann NY Acad Sci 762: 474-476, 1995.

SLUZEWSKA A, RYBAKOWSKI J, BOSMANS E, SOBIESKA M, BERGHMANS R, MAES M, WIKTOROWICZ K: Indicators of immune activation in major depression. Psychiatry Res 64: 161-167, 1996.

SUTCIGIL L, OKTENLI C, MUSABAK U, BOZKURT A, CANSEVER A, UZUN O, SANISOGLU SY, YESILOVA Z, OZMENLER N, OZSAHIN A, SENGUL A: Pro- and anti-inflammatory cytokine balance in major depression: effect of sertraline therapy. Clin Dev Immunol: 76396, 2007.

THE WORLD HEALTH ORGANIZATION MONICA PROJECT (MONITORING TRENDS AND DETERMINANTS IN CARDIOVASCULAR DISEASE): a major international collaboration. WHO MONICA Project Principal Investigators. J Clin Epidemiol 41: 105-114, 1988.

ZUNG WWK: A self-rating depression scale. Arch Gen Psychiatry 12: 63-70, 1965.

ZUNG WWK: The role of rating scales in the identification and management of the depressed patient in the primary care setting. J Clin Psychiatry 51: 72-76, 1990. 